\title{
Using Arrested Solid-Solid Multiphase Reactions in Geological Materials to Deduce the Rate of Crustal Uplift
}

W.E. Glassley and A. Meike

This article was submitted to Properties of Comples Inorganic Solids Volume II. International Alloy Conference Davos, Switzerland August 8-14, 1999

Lawrence Livermore National Laboratory

\section{March 13, 2000}




\section{DISCLAIMER}

This document was prepared as an account of work sponsored by an agency of the United States Government. Neither the United States Government nor the University of California nor any of their employees, makes any warranty, express or implied, or assumes any legal liability or responsibility for the accuracy, completeness, or usefulness of any information, apparatus, product, or process disclosed, or represents that its use would not infringe privately owned rights. Reference herein to any specific commercial product, process, or service by trade name, trademark, manufacturer, or otherwise, does not necessarily constitute or imply its endorsement, recommendation, or favoring by the United States Government or the University of California. The views and opinions of authors expressed herein do not necessarily state or reflect those of the United States Government or the University of California, and shall not be used for advertising or product endorsement purposes.

This is a preprint of a paper intended for publication in a journal or proceedings. Since changes may be made before publication, this preprint is made available with the understanding that it will not be cited or reproduced without the permission of the author.

This report has been reproduced directly from the best available copy.

Available to DOE and DOE contractors from the Office of Scientific and Technical Information P.O. Box 62, Oak Ridge, TN 37831

Prices available from (423) 576-8401 http://apollo.osti.gov/bridge/

Available to the public from the National Technical Information Service

U.S. Department of Commerce 5285 Port Royal Rd., Springfield, VA 22161 http://www.ntis.gov/

OR

Lawrence Livermore National Laboratory Technical Information Department's Digital Library http://www.llnl.gov/tid/Library.html 


\title{
USING ARRESTED SOLID - SOLID MULTIPHASE REACTIONS IN GEOLOGICAL MATERIALS TO DEDUCE THE RATE OF CRUSTAL UPLIFT.
}

\author{
William E. Glassley and Annemarie Meike \\ Earth and Environmental Sciences Directorate \\ Lawrence Livermore National Laboratory, Livermore, CA 94550 USA
}

\begin{abstract}
The history geological terrains experience can be traced as a series of temperature and pressure changes. Each change drives the system toward a new state of thermodynamic equilibrium. The resultant overprinted rock fabrics, textures and chemical heterogeneities can be difficult to interpret. However, if carefully chosen, features from the scale of kilometers to nanometers can be used to reconstruct the history of mountain systems. Uplift of the Sri Lankan Central Highlands was rapid enough to preserve well-developed symplectite textures, some of which represent arrested solid-state diffusion-controlled reactions of garnet $+\mathrm{O}_{2}$ to form orthopyroxene + plagioclase + magnetite, as the rocks were exhumed from over $30 \mathrm{~km}$ in the earth's crust. Our objective has been to determine the reaction mechanisms responsible for symplectite development, and to establish the time interval over which these reactions occurred, to constrain the rate of mountain uplift. Considering that the most rapid mechanism is solid state grain-boundary diffusion of oxygen, the reaction time can be constrained by bounding the rate of oxygen supply to the reaction site. The solid state grain boundary diffusion rate of oxygen has been inferred to be ca. $10^{\wedge}-14 \mathrm{~m} 2$-sec (Farver and Yund, 1991), but is sensitive to inferred grain boundary width. The range of rates thus determined allows the distinction between rapid uplift similar to that of the Himalayan Mountains, and the slow and progressive erosion of a less dramatic terrain. Further constraints on diffusion control and energetic relationships are determined from crystallographic relationships between the reactant and product phases, and submicron scale microstructures.
\end{abstract}




\section{INTRODUCTION}

The evolution of the Earth's crust is recorded in the chemical and physical characteristics of the mineral phases that make up the crust. This history is preserved as recrystallization events, which can include changes in mineral composition and/or mineral structure, or can be recorded as net transfer reactions in which there is a change in the assemblage of coexisting mineral phases. These changes occur in response to changes in pressure, temperature and stress conditions, which are the primary variables that affect rock properties.

Generally, the history of large-scale events, such as mountain building and continental collisions, often extend over many millions of years. Often these histories include periods of time during which the rocks being considered experienced high pressures $(0.1$ to $1 \mathrm{GPa})$ and high temperatures $\left(300\right.$ to $\left.900^{\circ} \mathrm{C}\right)$. The resulting history of pressure and temperature change (P-T history) thus tracks the up and down movement of a portion of the Earth's crust through time. Dating the rocks in such a sequence provides information concerning the time at which the rock sequence attained a particular pressuretemperature state, provided the date can be reliably tied to a specific mineral assemblage, a specific suite of micro-chemical properties, or a particular micro-structural characteristic. If a series of dates can be obtained at well-defined points along the P-T history, then the rate of movement of the crust can be determined.

Rates of change in P-T histories are useful for piecing together crustal history, since such data allow motion vectors to be determined. Plate tectonics is the conceptual framework within which the evolution of the Earth's crust is described. This paradigm relates events recorded in the crust to movements of crustal segments. The magnitude and orientation of movement vectors allow distinction to be made between the different regimes that cause destruction, formation and modification of crust.

Establishing movement rates on anything other than a multi-million year time scale has been difficult because of the lack of good benchmarks for mechanisms that can be used to record such events. Nevertheless, such data are required in order to refine models of plate motion, and to further develop understanding of the underlying mechanisms controlling plate dynamics.

In this report we present the preliminary determination of the rate of a specific diffusion-controlled, arrested net transfer reaction that potentially records a specific point along a P-T trajectory for a sequence of rocks from Sri Lanka. Further application of this approach may allow refinement of highly resolved motion vectors for crustal segments, thus contributing to a better understanding of plate movements and the mechanisms controlling plate tectonics.

\section{DIFFUSION CONTROLLED REACTIONS IN ROCKS}

Diffusion controlled processes are responsible for many of the key chemical characteristics that record P-T history. Compositional zoning within crystalline phases, inter-phase ion exchange, and net transfer reactions involving multiple crystalline phases are all diffusion controlled. Each of these diffusion-controlled processes could potentially be used to evaluate the time-resolved motion vectors, if the underlying diffusion controls 
could be determined. However, a major limitation in deciphering the relevant rates is uncertainty in the applicable diffusion coefficients. Diffusion coefficients derived for geological materials differ by many orders of magnitude, depending upon the relative importance of a fluid phase along grain boundaries. In certain cases, such as the formation of hornblende-spinel-orthopyroxene coronas around olivines (Ashworth, 1993) textures have been described in terms of fluid-absent grain-boundary and intra-crystalline $\mathrm{Al}$ diffusion, and have been used to infer that long time periods ( $>1$ million years) were required for corona growth. In contrast, corona growth has also been documented in carbonate-silicate experimental systems in which the total time duration of mineral development was tens of days, and the presence of a fluid phase was documented (Lutge and Metz, 1993).

Symplectites (Figure 1) are similar to corona textures in that a shell of product minerals surrounds a reactant mineral phase. In some cases the shell is complete, in others it is discontinuous. The product minerals develop when the free energy at the grain boundary exceeds that of a different but compositionally equivalent mineral assemblage. This condition has been observed to develop between pairs of minerals, as well as in response to changes in chemical potentials.

Figure 1. Schematic diagram of symplectite texture and phase relationships.. Note the difference in grain size and grain form between the mineral phases that had formed pripr to symplectite development (designated by "-P" for primary) and those minerals that form during symplectite growth (designated by "-S" for secondary). Figure modified from Sandiford et al. (1988). 
Symplectites commonly are worm-like intergrowths of two or three minerals. The large length to width ratio of these crystals, and their very small size, suggest that crystal interfacial energy is high and, hence, the duration of time at elevated temperature insufficient to allow grain coarsening. The long axis of the worm-like forms is generally at a high angle to the interface with the reactant mineral phase, thus providing a relatively high number of symplectite mineral grain boundaries per unit area of reactant mineral surface area. As discussed later, this is significant for models of symplectite growth in which grain boundary diffusion is the rate-limiting step. The textures indicate that reaction did not completely consume the garnet, providing a clear example of an arrested reaction relationships

\section{SRI LANKA PYROXENE-FELDSPAR-MAGNETITE SYMPLECTITES}

The geology of Sri Lanka (Fig. 2) is dominated by the Highland Series, which runs as a broad band in a NNE - SSW trend through the central part of the island. These rocks are high-grade metamorphic rocks which have experienced a complex metamorphic and structural history. This history includes an early recrystallization event between 1.94 and 1.1 billion years ago, followed by a series of deformations and recrystallizations, culminating in relatively rapid uplift sometime between 0.67 and 0.55 billion years ago (Sandiford et al., 1988; Kriegsman, 1991; Kehelpannala, 1991).

Figure 2. Geology of Sri Lanka. The samples were collected from outcrops near the city of Kandy. Map modified from Sandiford et al. (1988). 
Some interpretations suggest that the Highland Series has been emplaced over lower grade rocks during the last major recrystallization (e.g., Kriegsman, 1991). Nevertheless, there is general agreement that this complex history involves an early stage at very high temperatures $\left(\mathrm{ca} .900^{\circ} \mathrm{C}\right.$ ) at elevated pressures $(\mathrm{ca} .0 .8-1.0 \mathrm{Gpa})$. This period was followed by possibly protracted, nearly isobaric cooling, and then a dramatic increase in the rate of change of pressure with temperature, suggesting rapid uplift (Schenk et al., 1991: Fig. 3).

Figure 3. The inferred temperature-pressure pathway followed by the Highland Series rocks. The heavy shaded line, which is derived from the trajectory presented in Schenk et al. (1991), is their generalized interpretation of the conditions of recrystallization during cooling and uplift of the Highland Series rocks. Also shown are the P-T conditions determined by Faulhaber and Raith (1991) for the symplectites they analyzed from the Highland Series rocks. The P-T conditions computed for garnet and coexisting quartz inclusions in our samples are indicated, as are the conditions computed for the symplectites in this study. Because the absolute temperatures are unknown for our samples, we computed pressures, assuming the temperatures were between $600^{\circ} \mathrm{C}$ and $700^{\circ} \mathrm{C}$, based on the coexistence of garnet-orthopyroxene-plagioclase. We infer that the actual conditions of symplectite growth fall close to the inferred P-T trajectory of Schenk et al. (1991).

Within the Highland Series, near the city of Kandy, occurs a series of rock outcrops in which symplectites of orthopyroxene, plagioclase, and magnetite have developed around almandine garnets (Fig. 4). The symplectites developed in rocks that originally were composed of plagioclase feldspars, orthopyroxenes, hornblendes, biotites, garnet and quartz. 
Figure 4. Photomicrographs of Sri Lanka symplectites used in this study. a. without polarizing filter b. with polarizing filter. Largest figure dimension is $2.3 \mathrm{~mm}$. 
Although plagioclase feldspars, orthopyroxenes, hornblendes, biotites and quartz in the bulk rock show clear evidence of strain, the symplectite grains do not. Hence, the minerals composing the symplectite are generally compatible with conditions suitable for orthopyroxene stability, but they post date the deformation period.

The garnets that have symplectite surrounding them contain inclusions of plagioclase and quartz. Quartz also occurs within the symplectites at the garnet-symplectite interface as a product mineral phase. This stable coexistence of garnet + quartz demonstrates that the symplectites did not form in response to the reaction:

$$
\left(\mathrm{CaMg}_{2}\right) \mathrm{Al}_{2} \mathrm{Si}_{3} \mathrm{O}_{12}+\mathrm{SiO}_{2} \Leftrightarrow \mathrm{CaAl}_{2} \mathrm{Si}_{2} \mathrm{O}_{8}+2 \mathrm{MgSiO}_{3}
$$

Instead, the reaction relationship represented by the symplectite must represent a change in some chemical condition affecting the external grain surfaces of the garnet, and not a change in intensive parameters such as temperature or pressure.

We propose that the actual reaction responsible for symplectite growth was controlled by oxygen availability:

$$
\begin{gathered}
\left(\mathrm{Ca}_{0.6} \mathrm{Fe}^{+2}{ }_{1.9} \underset{\text { (garnet) }}{\left.\mathrm{Mg}_{0.5}\right)\left(\mathrm{Fe}^{3+} \mathrm{Al}_{1.8}\right) \mathrm{Si}_{3} \mathrm{O}_{12}}+0.125 \mathrm{O}_{2} \Leftrightarrow\right. \\
\underset{\text { (orthopyroxene) }}{1.25} \underset{\text { (plagioclase) }}{\left(\mathrm{Fe}^{+2} \mathrm{Mg}_{0.4}\right) \mathrm{SiO}_{3}}+\underset{\text { (quartz) }}{0.6 \mathrm{CaAl}_{2} \mathrm{Si}_{2} \mathrm{O}_{8}}+\underset{\text { (magnetite) }}{0.55 \mathrm{SiO}_{2}}+\underset{\mathrm{Fe}^{+2}\left(\mathrm{Fe}^{+3}{ }_{1.08} \mathrm{Al}_{0.92}\right) \mathrm{O}_{4}}{0.65}
\end{gathered}
$$

The stoichiometry of this reaction is based on microprobe analyses of the compositions of the mineral phases occurring at the garnet - symplectite interface, with the exception of the spinel phase (magnetite), the composition of which is based on partial analyses of these phases, and their optical properties in reflected light. This reaction suggests that the change in chemical condition was related to the oxygen fugacity.

The outer edge of the symplectite defines the original location of the garnet grain boundary, prior to reaction. Symplectite development occurs as a volume replacement of garnet by the nearly compositionally equivalent assemblage orthopyroxene-plagioclasemagnetite-quartz. In order to sustain symplectite growth, oxygen diffusion must occur along the symplectite grain boundaries.

Within the symplectite occur domains in which the optical orientation of separate orthopyroxene grains is the same. This suggests that mineral growth during garnet breakdown is controlled by some topotactic relationship with the underlying garnet.

Optical examination suggests that more distant (earlier formed) symplectite grains are more equant than those immediately adjacent to the garnet (Fig. 4). Measurement of the grain dimensions is consistent with this inference (Fig. 5). This suggests grain coarsening has occurred over the lifetime of the reaction process that generated the symplectites. As noted below, this point may play a role in explaining the arrested state of these reactions.

\section{OXYGEN GRAIN BOUNDARY DIFFUSION AND SYMPLECTITE FORMATION}

Diffusion in geological materials has been the subject of several recent investigations (Ashworth, 1993; Farver and Yund, 1990, 1991, 1995a,b, 1996 1998; Ashworth et al., 1998 
a,b; Obrien, 1999). These results add to a large body of literature that has shown through various means and in a wide range of materials that intercrystalline or volume diffusion is orders of magnitude slower than fluid mitigated grain boundary diffusion. Debate still exists, however, over several key aspects of what is considered to be grain boundary diffusion in the absence of a fluid phase. Some studies (Ashworth, 1993) have suggested that fluid absent grain boundary diffusion is virtually indistinguishable from volume diffusion, and thus the corresponding diffusion coefficients are assigned approximately equivalent values. Others have presented experimental results purporting to demonstrate that fluid-absent grain boundary diffusion coefficients are intermediate between those of volume diffusion and fluid-mitigated grain boundary diffusion (Farver and Yund, 1991). Important in these debates are questions concerning the width of grain boundaries, which may be expected to change with pressure and temperature, and the physics of atomic migration in these regions.

Le Claire (1963) developed a formalism to evaluate analytical data obtained from laboratory experiments that consider grain boundary diffusion, which is expressed as:

$$
\mathrm{D}^{*} \delta=\left[(\mathrm{d} \operatorname{lnc}) /\left(\mathrm{dy}{ }^{6 / 5}\right)\right]^{-5 / 3}(4 \mathrm{D} / \mathrm{t})^{1 / 2}\left[(\mathrm{~d} \operatorname{lnc}) /\left(\mathrm{d}\left(\eta \beta^{-1 / 2}\right)^{6 / 5}\right)\right]^{5 / 3}
$$

where $D^{*}$ is grain boundary diffusion coefficient, $\delta$ is grain boundary width, $\mathrm{c}$ is the concentration at depth $\mathrm{y}, \mathrm{D}$ is the volume diffusion coefficient, $\eta$ is a dimensionless number dependent on $\mathrm{D}, \mathrm{y}, \boldsymbol{\delta}$ and time, and $\beta$ is a parameter dependent on $\mathrm{D}, \mathrm{D}^{*}, \boldsymbol{\delta}$ and time. This formalism is based on rearrangement and simplification of the equations derived by Whipple (1954). This formalism is valid within limits described by Le Claire, as confirmed by Chung and Wuensch (1996). The fundamental limit is that $\beta$ be greater than approximately 10 . When applied, these limits result in the following simplified version of (1):

$$
\mathrm{D} * \delta=[(\mathrm{dlnc}) /(\mathrm{dy} / 5)]^{-5 / 3}(4 \mathrm{D} / \mathrm{t})^{1 / 2}(0.661)
$$

Using the approach proposed by Le Claire, Farver and Yund (1991, 1995a,b, 1996, 1998) have analyzed the results of a series of experiments they have conducted in which they consider grain boundary diffusion of oxygen, potassium and calcium in geological materials. From these analyses they have proposed grain boundary diffusion coefficients for these elements.

We have opted to use their diffusion coefficient for fluid-absent oxygen grain boundary diffusion to evaluate the time duration over which the symplectite developed in the Sri Lanka sample described above. Our interest is in establishing a time limit for the duration of reaction. We believe that using this diffusion coefficient will provide a means for defining a time interval over which it is likely symplectite growth occurred. These results are preliminary for several reasons.

First, the effective grain boundary width remains unknown. Formation of the symplectites occurred at highly elevated temperatures and pressures, and evidently during uplift. There are no experimental data for grain boundary widths under such conditions. We have therefore taken 1e-9 meters as a first approximation of an average grain boundary width for the present polymineralic assemblage for similar reasons to those discussed by Farver and Yund (1991). They consider estimates for metals and simple oxides as well as 
ex-post facto transmission electron microscope (TEM) observations (not at pressure or temperature) of more complex silicate structures. The value of $1 \mathrm{e}-9$ meters should be near the lower limit of possible values for the polymineralic simplectite assemblage. Grain boundary widths, Farver and Yund (1991) note, must be on the order of a unit dislocation width (Burgers vector of albite and orthoclase is $0.8 \mathrm{~nm}$ ).

Figure 5. Width (a.) and length (b.) dimensions of seventy-four symplectite orthopyroxene grains, as a function of distance from garnet grain edge. All distances are in millimeters. Also shown is the length to width ratio of the orthopyroxene grains, as a function of distance from the garnet (c.). 
Second, we have assumed that grain boundary properties in these natural rocks are similar to the mineralogically distinct (quartz vs plagioclase-orthopyroxene-magnetitequartz) and laboratory annealed fine grained quartz samples used in the Farver and Yund (1991) experiments. It is unlikely that the grain boundaries are identical, but the differences, and their significance with respect to the magnitude of the diffusion coefficients are unknown. In the absence of reference data that would allow us to better characterize the natural grain boundaries, we will use the data from the reported experiments and emphasize the inherent uncertainties that must be kept in mind.

Third, in order to apply the Farver and Yund diffusion coefficients it is necessary to assume that the role of a fluid phase was the same. This cannot be assured. It is conceivable that the grain boundaries in the Sri Lanka samples were partially wetted by a fluid phase of unknown composition. For the present, we will simply assume that fluid condition along the grain boundaries in the different sets of materials was similar.

We can constrain the time duration of the reaction by considering two limits. The maximum distance over which diffusion could have occurred is the width of the symplectite zone. Although this width varies from location to location, a value of le-4 meters is about average. We also assume in this case that the diffusion gradient was linear over this distance, and was constant with time. The minimum distance over which diffusion occurred cannot be established directly, but for calculational purposes we assume that it was approximately equivalent to that achieved in the laboratory experiments of Farver and Yund (1991)(6e-6 meters). Assuming that the rate-limiting step in the reaction progress was oxygen diffusion, we solve for the time duration required for oxygen to diffuse these distances. The results for these calculations are shown in Figure 6.

\section{DISCUSSION}

The results in Figure 6 show that the maximum time over which symplectite growth occurred was approximately 500 years, and the minimum time was a few weeks, depending upon the actual diffusion distance. From the physical perspective argued in the paragraph below, the longer time period is unlikely.

Initiation of the symplectite growth at the original garnet surface must have begun when the P-T- $-\mathrm{O}_{2}$ conditions achieved values outside the garnet stability field. Symplectite growth would then be limited by oxygen diffusion along symplectite grain boundaries. Two possible reaction pathways can be postulated that would reflect the evolution of the symplectite, once its development had been initiated. Either the diffusion gradient at the garnet interface maintained a constant value and migrated inward toward the garnet, or the gradient decreased with time as the symplectite grew (Figure 7). In the case of the former scenario, the gradient would migrate at a rate equivalent to the diffusion rate. In this case, the total time required to achieve a symplectite thickness of $1 \times 10^{-4}$ meters would be approximately 0.1 years, at $600^{\circ} \mathrm{C}$.

Were the diffusion gradient to have decreased with time, oxygen would have been depleted in the region immediately outside the original garnet surface. The decrease in oxygen fugacity would be expected to be recorded in the minerals adjacent to the original garnet surface. However, neither a change in oxide mineralogy nor evidence of reactions involving reduction of iron in mixed $\mathrm{Fe}^{++}-\mathrm{Fe}^{++}$phases is seen in this area. Hence, we 
conclude that oxygen flux along symplectite grain boundaries occurred at a rate approximately equivalent to that at the symplectite-garnet interface.

Figure 6. Diffusion distance (in meters) as a function of time (years). The line labeled "Grain boundary width $=10^{-9} \mathrm{~m}$ " indicates time-distance correlation for the computed set of conditions described in the text, which assumes a temperature of ca. $600^{\circ} \mathrm{C}$. The shaded region encloses the possible range of distances over which diffusion operated during symplectite growth. The maximum distance is the approximate measured width of the symplectite. The minimum distance is that inferred to be operative in the experiments reported by Farver and Yund (1999), which is 6e-6 meters. 
Table 1. Values, sources and assumptions for key variables used in calculation of diffusion distances.

\begin{tabular}{ccc}
\hline Variable & Assigned Value & Comment \\
\hline Grain Boundary Width & $1.0 \mathrm{E}-9$ meters & $\begin{array}{c}\text { Assumed from Farver and } \\
\text { Yund, 1991 }\end{array}$ \\
Oxygen Diffusion Coefficient & $5.0 \mathrm{E}-15$ & Ibid, assuming $600^{\circ} \mathrm{C}$ \\
$\begin{array}{c}\text { Concentration Gradient } \\
(\mathrm{dlnC})\end{array}$ & 3.4 & Ibid \\
\hline
\end{tabular}

These results imply that the symplectite textures formed over a few week period during decompression. This short duration reflects the mechanism responsible for this grain growth - grain boundary diffusion of a relatively mobile component. This is in contrast to retrograde corona textures formed around olivines (Ashworth, 1993), for example, in which the rate-limiting step in the corona growth is $\mathrm{Al}$ volume diffusion. The mechanism responsible for the symplectite-forming reaction cannot be resolved between changes in pressure, temperature or oxygen fugacity. It is likely that a combination of changes involving these variables was responsible, since these variables are coupled.

Cessation of the reaction could have been the result of changes in oxygen fugacity, or changes in the mobility of oxygen along the grain boundaries. The latter may have been at least partially responsible since, as previously noted, the symplectite grains become less elongate and coarsen with time. This change has the consequence of diminishing the density of grain boundaries that are oriented perpendicular to the garnet surface, making more tortuous the oxygen diffusion pathway. We speculate that a point was eventually reached at which oxygen diffusion was choked off due to this reorganization of grain boundaries.

\section{CONCLUSIONS}

The results presented here suggest that symplectite growth around garnets in this environment was controlled by changes in oxygen fugacity. This change was associated with decompression and could result from any combination of changes in P-T and oxygen partial pressure.

Available evidence suggests that the duration of the symplectite growth was on the order of a few weeks. This short duration reflects the mechanism responsible for this grain growth - grain boundary diffusion of a relatively mobile component. Far slower reactions have been estimated for mechanisms such as retrograde corona textures in which the ratelimiting step is $\mathrm{Al}$ volume diffusion. The resulting diffusion coefficients are approximately 
nine orders of magnitude larger, and the inferred time duration for the corona growth are millions of years.

These results emphasize that trajectories of inferred pressure-temperature pathways in P-T diagrams grossly integrate complex histories, and do not provide any direct information about rate of crustal movement. To fully understand crustal evolution, methods resulting data can then be used to place within a plate tectonics framework the vertical component of motion specific crustal terrains have experienced.

Uncertainties in the calculations we have performed primarily reflect the use of values for variables, such as grain boundary width, that were obtained from measurements on materials (metals and simple oxides) which are not close analogs to complex silicates. Also, the conditions under which the measurements were made do not closely approximate the extreme temperatures and pressures experienced by the geological materials. Obtaining more accurate measurements or calculated values for geologically appropriate mineral phases is a significant challenge but, when accomplished, will greatly enhance our ability to better constrain the evolutionary history of the crust and greatly expand our ability to understand large scale geological processes.

* This work was performed under the auspices of the U.S. Department of Energy by University of California Lawrence Livermore National Laboratory under contract No. W-7405-Eng-48.

\section{REFERENCES}

Ashworth, J.R., 1993, Fluid-absent diffusion kinetics of Al inferred from retrograde metamorphic coronas. Am. Min. 78:331.

Ashworth, J. R., Sheplev, V. S. Bryxina, N. A., Kolobov, V. Y. and Reverdatto V.V. 1998a, Diffusion-controlled corona reaction and overstepping of equilibrium in a garnet granulite, Yenisey Ridge, Siberia. J. Met. Geol. 16:231.

Ashworth, J. R., Sheplev, V. S. Bryxina, N. A., Kolobov, V. Y. and Reverdatto V.V. $1998 \mathrm{~b}$, Textures of diffusion-controlled reaction in contact-metamorphosed $\mathrm{Mg}$-rich granulite, Kokchetav area, Kazakhstan. Mineral. Mag. 62:213.

Chung, Y-C. and Wuensch, B. J., 1996, Assessment of the accuracy of Le Claire's equation for determination of grain boundary diffusion coefficients from solute concentration gradients. Materials Letters. 28: 47.

Farver, J.R. and Yund, R.A., 1990, The effect of hydrogen, oxygen, and water fugacity on oxygen diffusion in alkali feldspar. Geochim Cosmochim Acta 54:2953.

Farver, J.R. and Yund, R.A., 1991, Measurement of oxygen grain boundary diffusion in natural, fine-grained, quartz aggregates. Geochim Cosmochim Acta 55:1597.

Farver, J.R. and Yund, R.A., 1995a, Grain boundary diffusion of oxygen, potassium and calcium in natural and hot-pressed feldspar aggregates. Contrib. Mineral. Petrol. 118:340.

Farver, J.R. and Yund, R.A., 1995b, Interphase boundary diffusion of oxygen and potassium in K-feldspar/quartz aggregates. Geochim Cosmochim Acta 59:3697. 
Farver, J.R. and Yund, R.A., 1996, Volume and grain boundary diffusion of calcium in natural and hot-pressed calcite agregates. Contrib. Mineral. Petrol. 123:77.

Farver, J.R. and Yund, R.A., 1998, Oxygen grain boundary diffusion in natural and hotpressed calcite agregates. Earth Planet. Sci. Lets. 161:189.

Faulhaber, S. and Raith, M., 1991, Geothermometry and geobarometry of high-grade rocks: a case study on garnet-pyroxene granulites in southern Sri Lanka. Min. Mag. 55:33.

Kehelpannala, K.V. W., 1991, Structural evolution of high-grade terrains in Sri Lanka with special reference to the areas around Dodanaslanda and Kandy, in:The Crystalline Crust of Sri Lanka, Part I, A. Kroner, ed., Geological Survey Department, Prof. Paper No. 5, Republic of Sri Lanka, Colombo.

Kriegsman, L., 1991, Structural geology of the Sri Lanka basement - A preliminary review, in:The Crystalline Crust of Sri Lanka, Part I, A. Kroner, ed., Geological Survey Department, Prof. Paper No. 5, Republic of Sri Lanka, Colombo.

Le Claire, A.D. 1963. The analysis of grain boundary diffusion measurements. Brit. J. Appl. Phys. 14:351.

Luttge, A. and Metz, P. 1993. Mechanism and kinetics of the reaction- 1dolomite plus 2quartz $=1$ diopside plus $2 \mathrm{CO} 2-$ a comparison of rock-sample and of powder experiments. Contr. Min. Pet. 115:155.

O'Brien, P. J., 1999, Assymetric zoning profiles in garnet from HP-HT granulite and implications for volume and grain-boundary diffusion. Mineral. Mag. 63:227.

Sandiford, M., Powell, R., Martin, S.F., and Perera, L.R.K., 1988, Thermal and baric evolution of garnet granulites from Sri Lanka. J. Metamorp. Geol. 6:351.

Schenk, V., Raase, P., and Schumacher, R., 1991, Metamorphic zonation and P-T history of the Highland Complex in Sri Lanka, in:The Crystalline Crust of Sri Lanka, Part I, A. Kroner, ed., Geological Survey Department, Prof. Paper No. 5, Republic of Sri Lanka, Colombo.

Whipple, R.T.P., 1954, Concentration contours in grain boundary diffusion. Philos. Mag. 45:1225. 


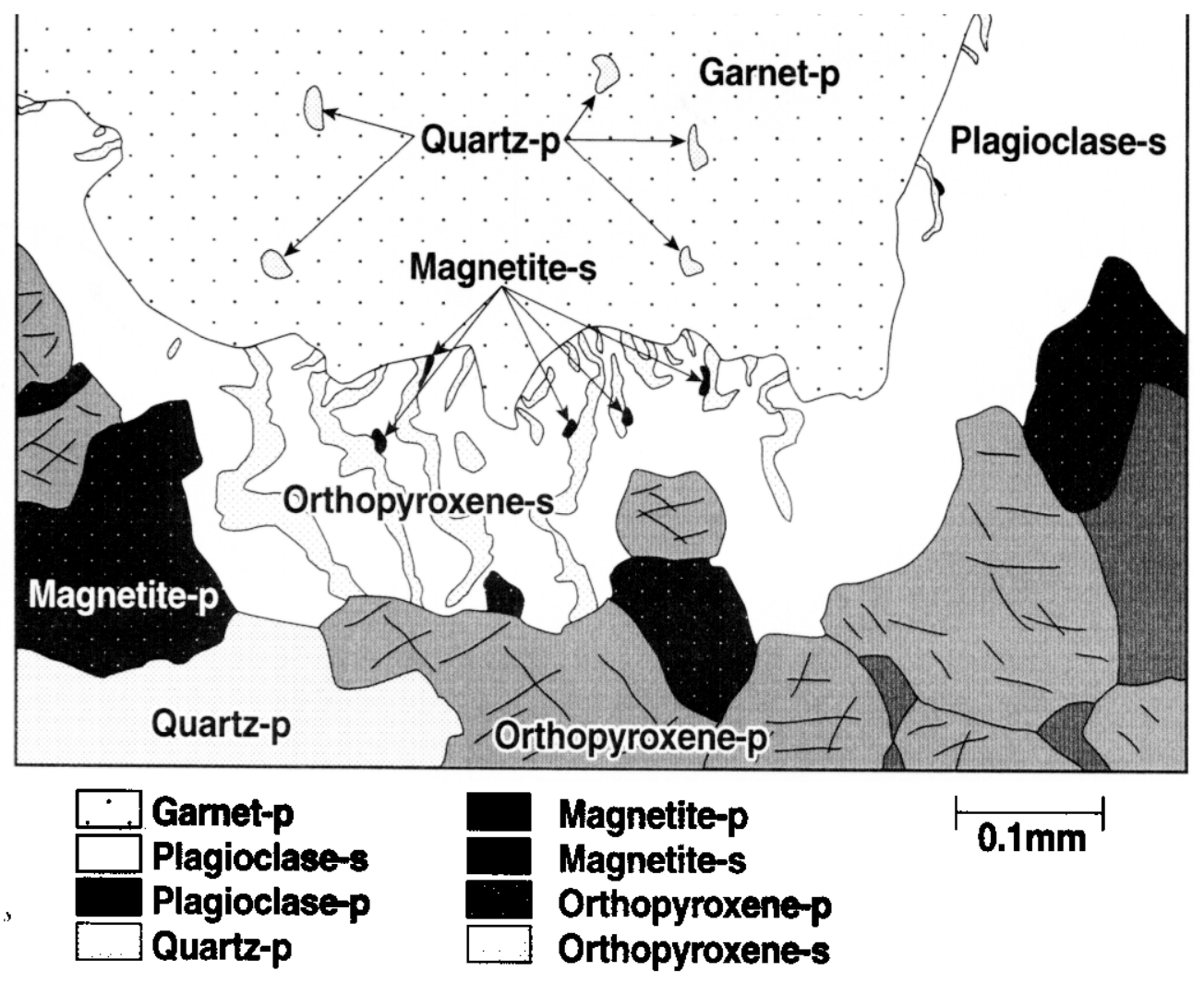




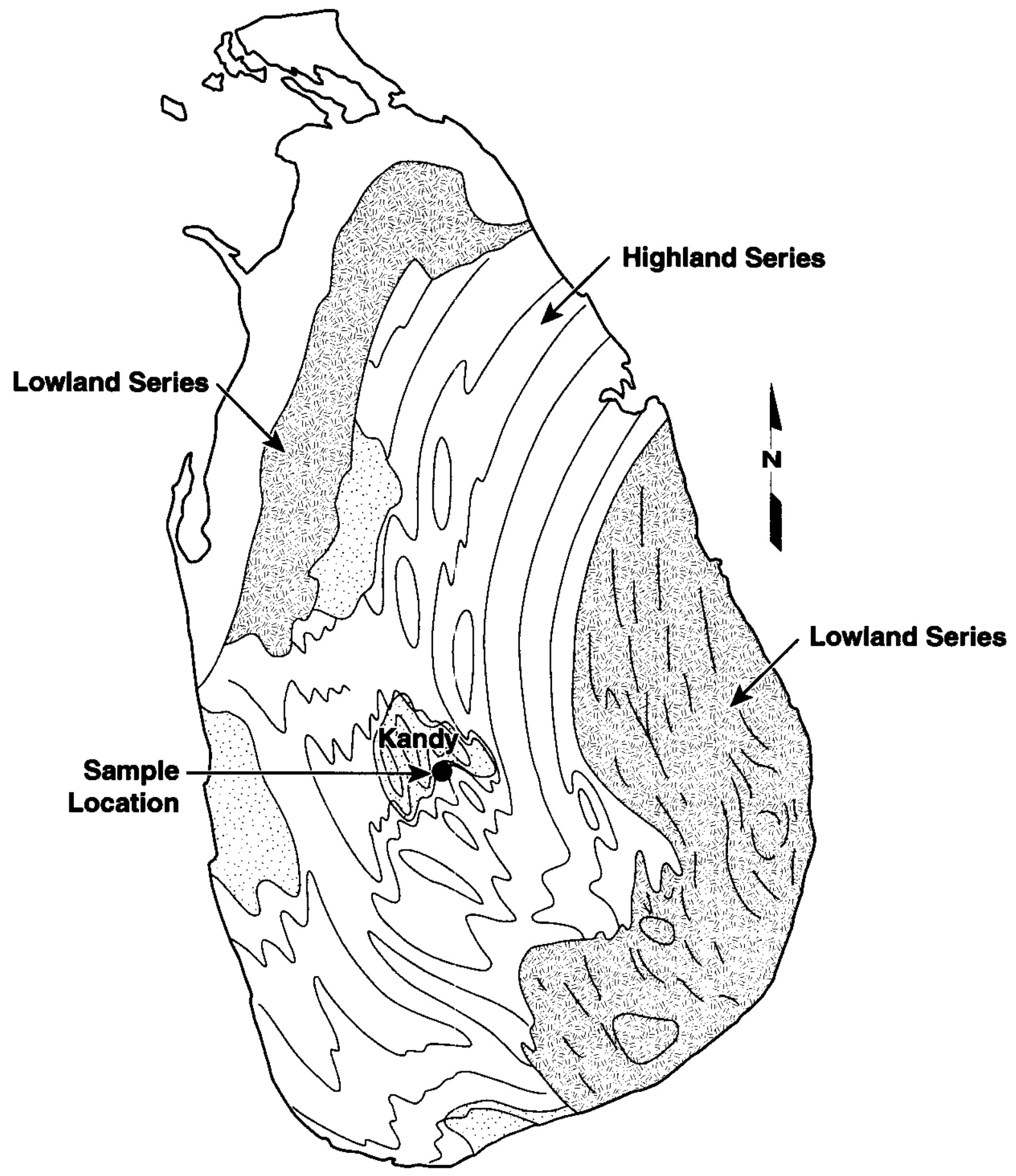




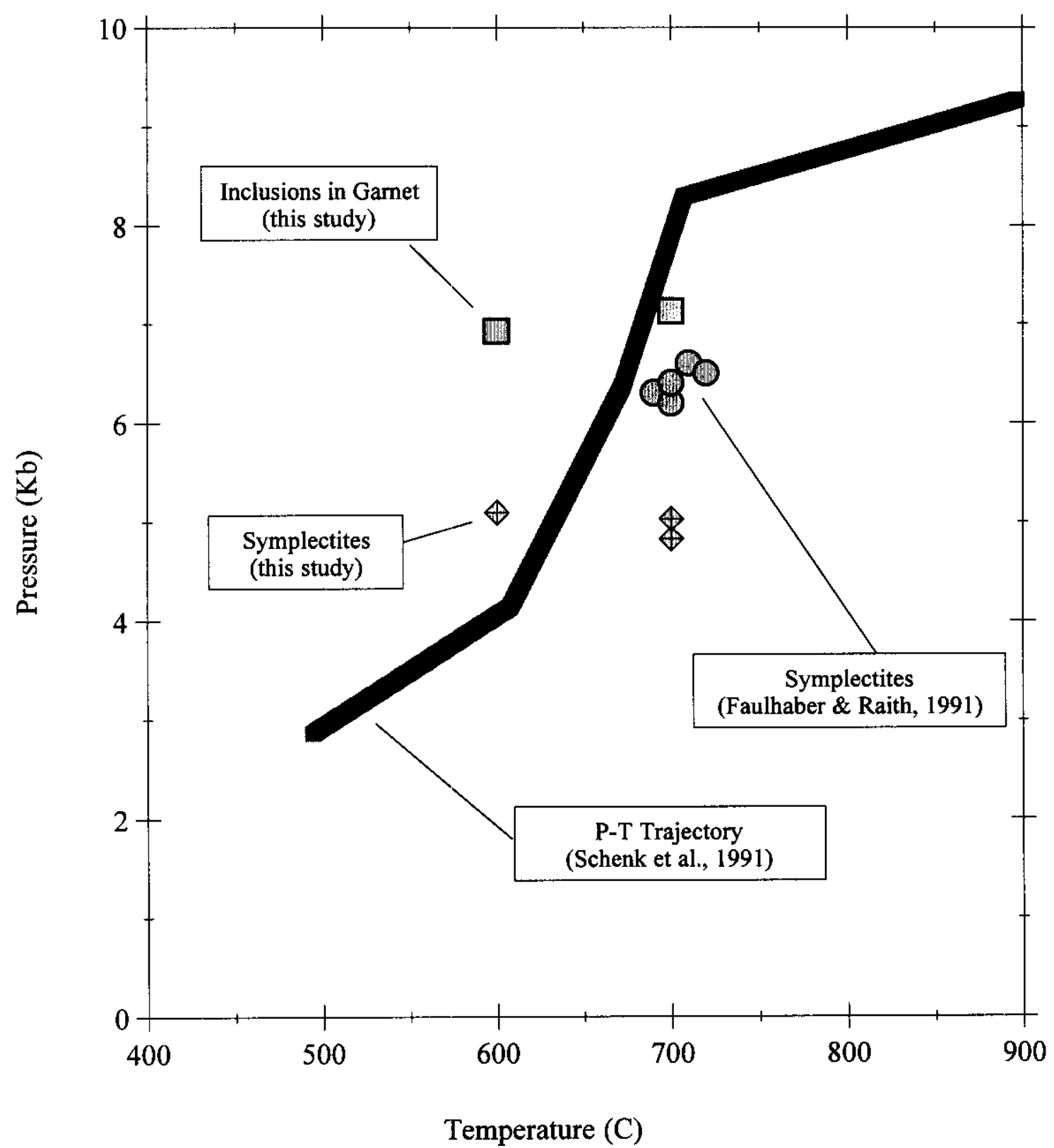

Figure 3 


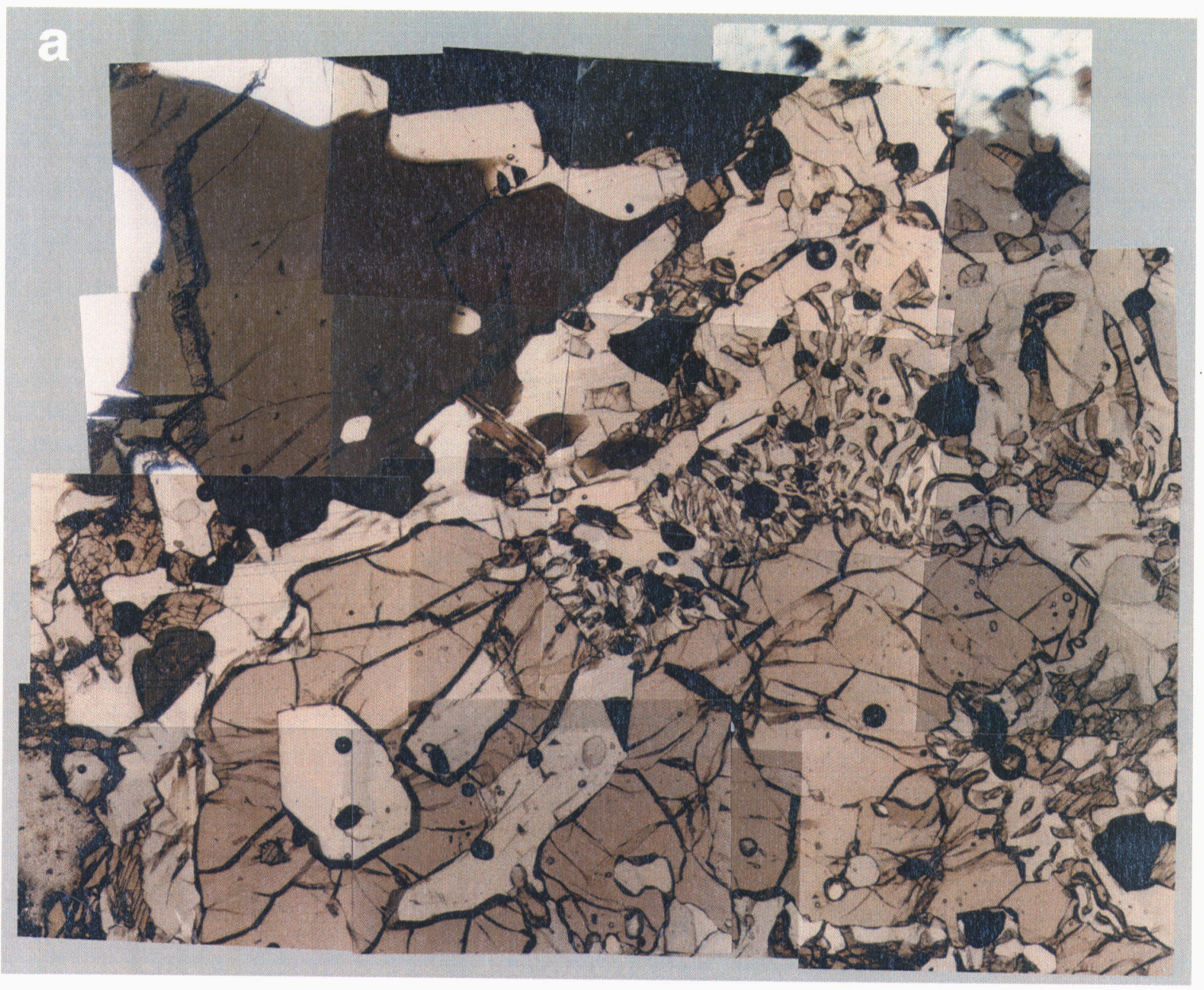




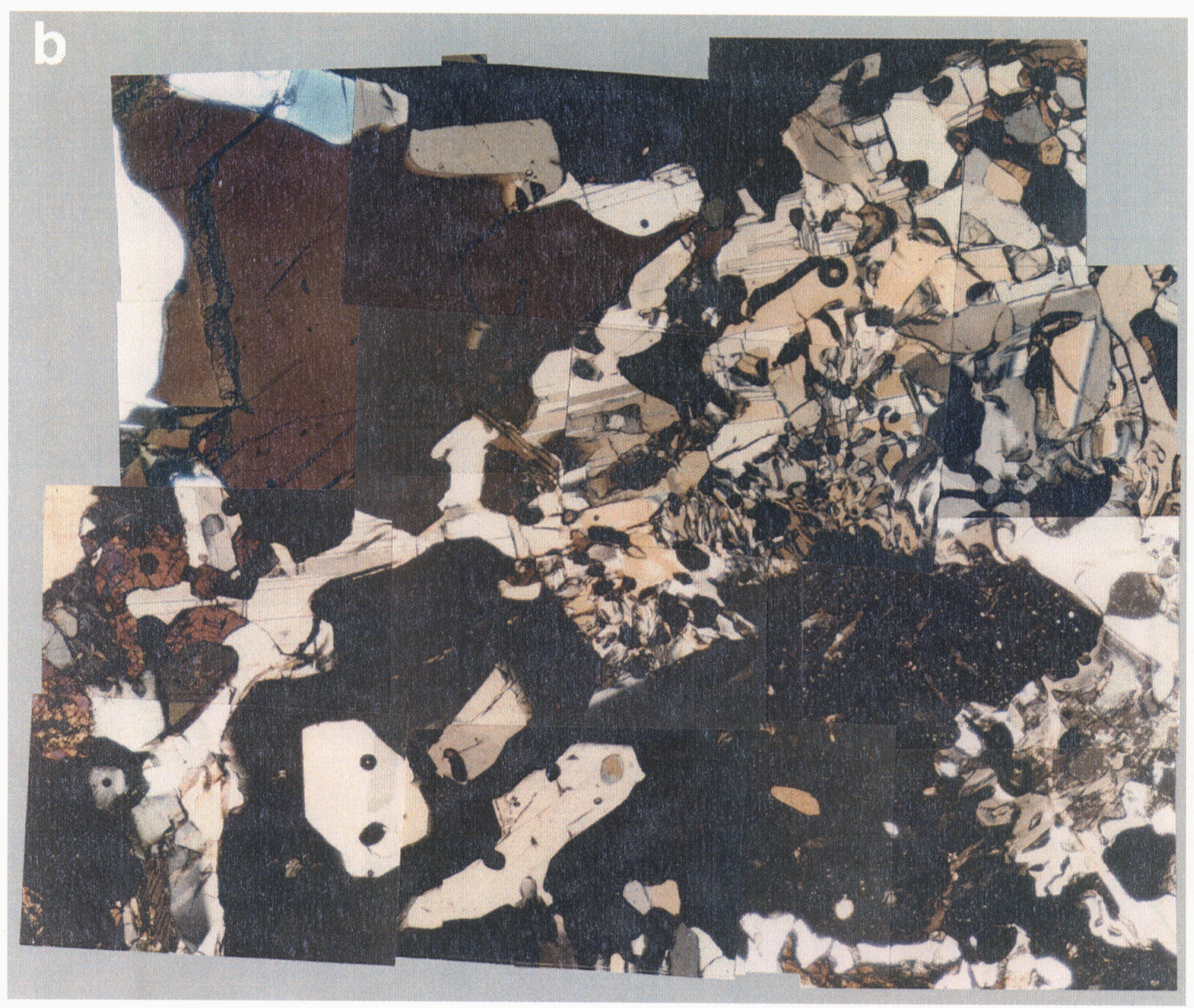



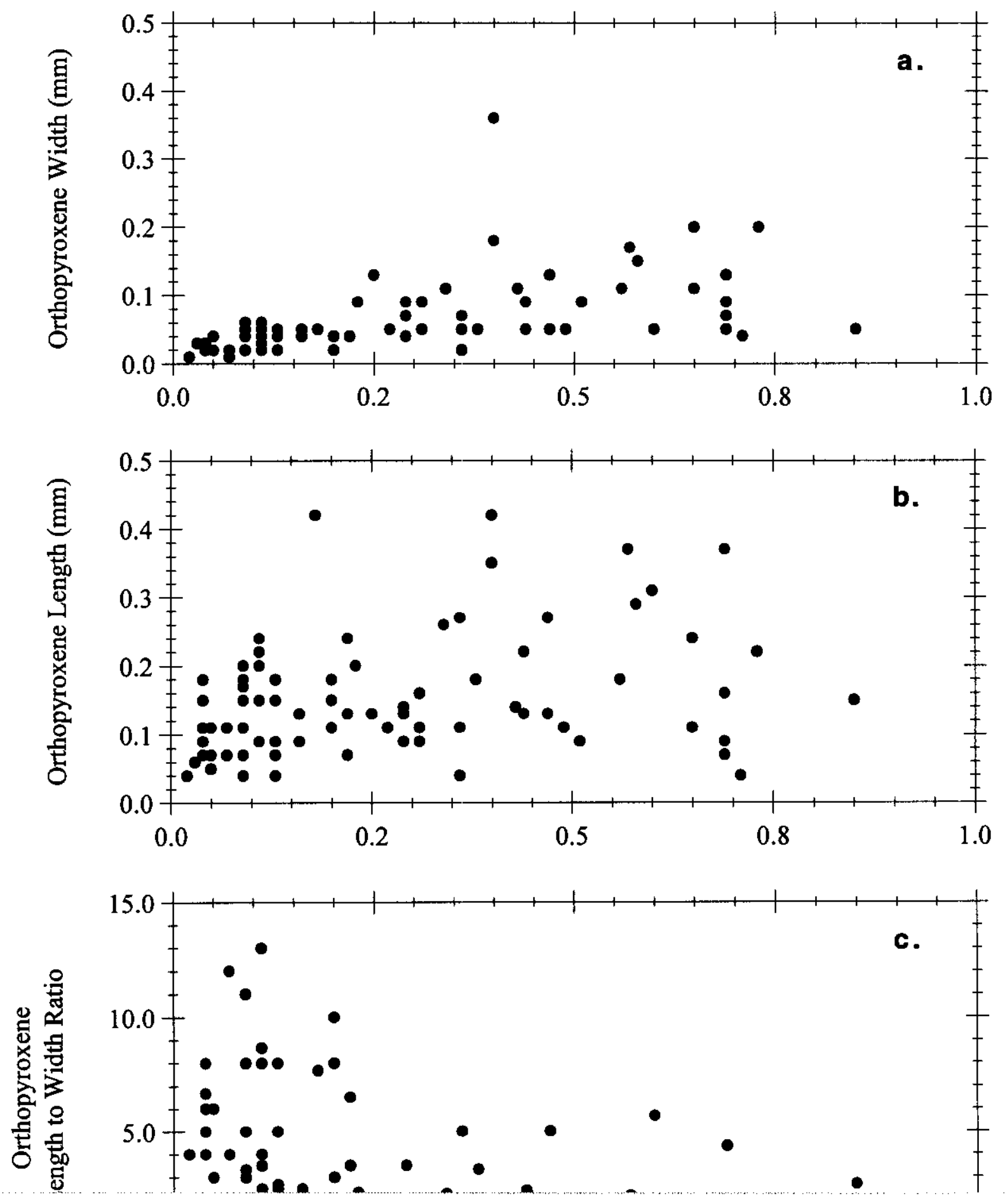


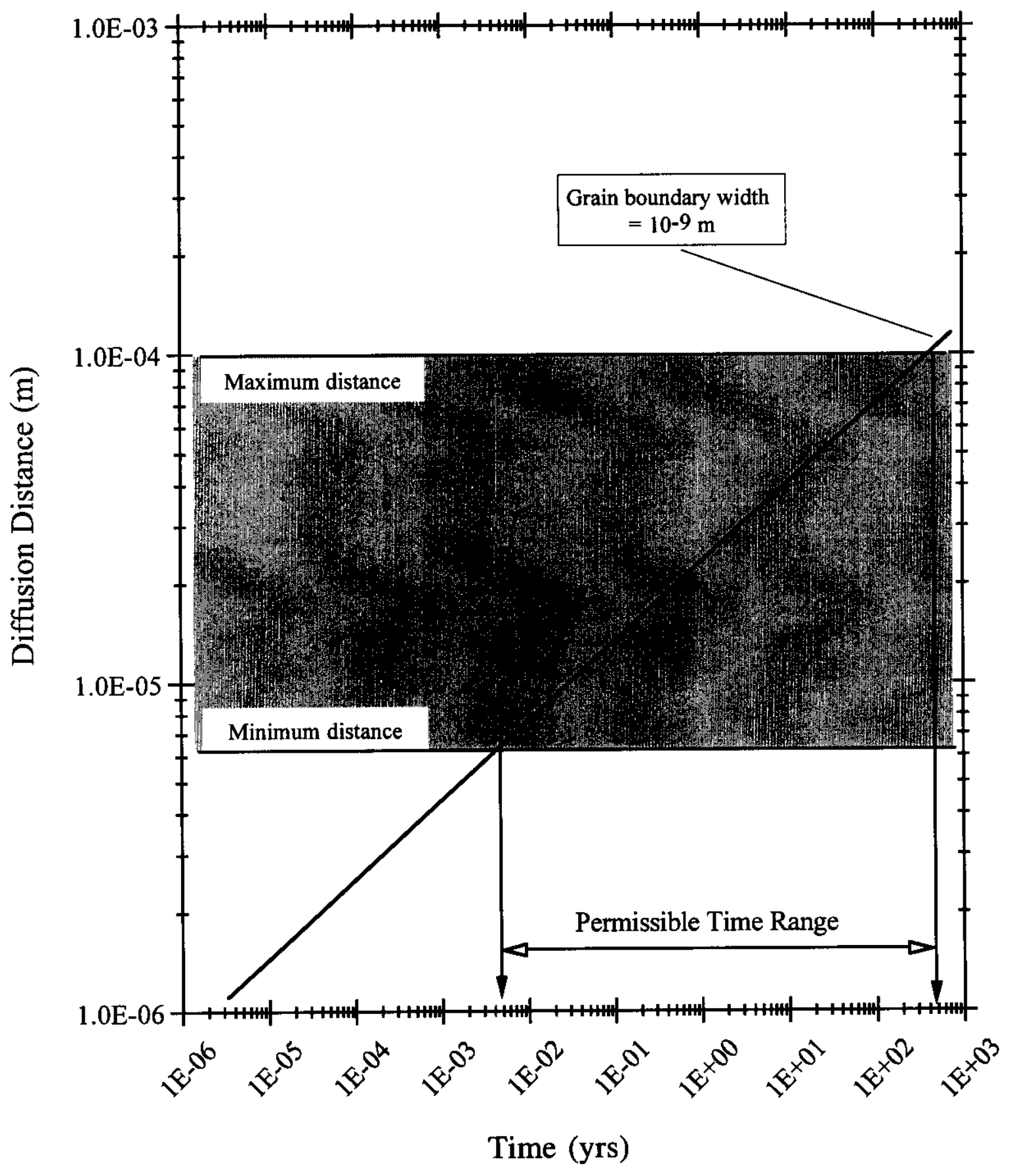

Figure 6 